\section{ISSN 2525-6904}

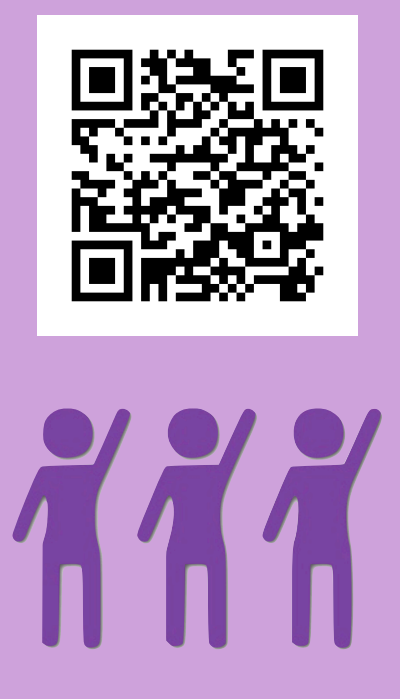

ARTIGOS

"A luta continua, companheiros... mas não para todos"

O esvaziamento das pautas LGBT no Sindicato de Trabalhadores em Educação da Universidade Federal do Rio de Janeiro ${ }^{1}$

Diego Santos Vieira de JeSUS, ESPM-Rio

Henrique de Oliveira Santos Vieira de JESUS, UFRJ

O objetivo é examinar o esvaziamento das discussões sobre direitos civis e trabalhistas LGBT no Sindicato dos Trabalhadores em Educação da Universidade Federal do Rio de Janeiro (SINTUFRJ). O argumento central aponta que o SINTUFRJ assumiu papel primordial na mobilização contra a precarização do trabalho dos técnicoadministrativos em educação (TAEs) na UFRJ e nas demais universidades federais no Brasil. Entretanto, o engajamento do SINTUFRJ na transformação dos TAEs em sujeitos políticos e sociais não pressupôs a eliminação de padrões heteronormativos no estabelecimento de objetivos, estratégias e mecanismos de reivindicação sindicais, de forma a se enfraquecer a atuação do grupo de trabalho LGBT do SINTUFRJ e se reduzir o peso das temáticas LGBT nas propostas do sindicato.

PALAVRAS-CHAVE: Heteronormatividade. Sindicalismo. Técnicoadministrativo em educação. Globalização. Universidades federais.

1 Uma versão inicial e reduzida dessa discussão foi apresentada em 2016 no VIII Congresso Internacional de Estudos sobre a Diversidade Sexual e de Gênero, sob o título 'A luta continua, companheiros (mas não para todos)!': a heteronormatividade no Sindicato dos Trabalhadores em Educação da Universidade Federal do Rio de Janeiro". 
"A luta continua, companheiros... mas não para todos": o

\section{Introdução}

O Sindicato dos Trabalhadores em Educação da Universidade Federal do Rio de Janeiro (UFRJ), o SINTUFRJ, tem como papel principal lutar pela valorização dos trabalhadores técnicoadministrativos em educação (TAEs) da UFRJ. Seu papel é fomentar na base as discussões e formular propostas para encaminhá-las às plenárias nacionais da Federação de Sindicatos dos Trabalhadores TécnicoAdministrativos em Instituições de Ensino Superior Públicas do Brasil (FASUBRA), que tem por objetivo reunir todos os sindicatos de base dos TAEs das universidades públicas federais. O SINTUFRJ tem uma relevância muito grande pela suas dimensão e importância para as universidades públicas federais do Brasil, já que orienta as discussões nas demais universidades públicas federais. A FASUBRA traz para discussão as decisões das bases e formula as propostas a serem discutidas pelos servidores e pelo Governo Federal, o que baliza as políticas a serem instituídas pela Administração Pública para regular as relações de trabalho dos TAEs (SINTUFRJ, 2016).

Tendo em vista a pluralidade dessas políticas, o SINTUFRJ optou pela criação de Grupos de Trabalho (GTs), em que temáticas específicas, como gênero e raça, começaram a ser debatidas mais detalhadamente, visando à proposição de ações e estratégias de luta mais específicas de acordo com a particularidade dos mecanismos de exclusão que incidem sobre uma série de sindicalistas na UFRJ e na própria sociedade. O contexto de criação desses GTs coincide, em grande parte, com a segunda metade da década de 2000 e o início da década de 2010, período no qual a motivação para a sua existência advinha, em grande parte, do crescimento das discussões sobre temas como raça, orientação sexual e identidade de gênero na própria universidade, estimuladas pelos debates acadêmicos promovidos por docentes e discentes acerca dessas temáticas, pelo maior envolvimento dos TAEs nas discussões sobre políticas que impactavam a todos os grupos componentes da comunidade universitária e pelas orientações que vinham de entidades nacionais, como a FASUBRA (FASUBRA, 2014).

Grande parte desses debates teve seu ápice durante as gestões de lideranças sindicais e reitores alinhados com propostas mais progressistas no Poder Executivo, particularmente durante as presidências de Luiz Inácio Lula da Silva e Dilma Rousseff. Ainda que os momentos fossem mais propícios ao desenvolvimento de discussões 
sobre políticas mais robustas voltadas para a proteção de grupos socialmente excluídos dentro da própria comunidade de TAEs, a maior parte dessas discussões apenas gerou orientações gerais para a atuação do SINTUFRJ, sem que houvesse planos de ação mais específicos que detalhassem ações a serem tomadas pelos sindicalistas. Além disso, o abandono e a negligência de grande parte dos TAEs em relação a essas causas mostraram-se muito ligados ao entendimento, por eles, de que as causas primordiais do SINTUFRJ estavam ligadas às questões salariais e ao relacionamento dos trabalhadores com as entidades públicas quanto às condições econômicas no ambiente de trabalho, mas não à inclusão de novas pautas relacionadas a temas que pareciam escapar às reivindicações tradicionais do sindicato. Nesse sentido, torna-se possível entender, por exemplo, por que os movimentos feministas ganharam cada vez mais espaço como mobilizações de massas ao redor do mundo, mas suas reivindicações entravam superficial ou marginalmente ou não eram incorporadas aos debates no SINTUFRJ, tendo em vista a sua concepção como elementos acessórios ou que tangenciavam os objetivos primordiais da entidade.

Em tal contexto, o SINTUFRJ propôs a criação do GT-LGBT para discutir as questões pertinentes a essas temáticas junto aos TAEs da UFRJ. Apesar da iniciativa de criação desse GT, seu funcionamento foi quase nulo. Em novembro de 2014, ocorreu o primeiro Seminário LGBT da FASUBRA, que girou em torno de discussões sobre direitos civis e trabalhistas da comunidade LGBT. No que diz respeito aos direitos civis, foi realizada uma crítica à cultura heteronormativa e constatada a necessidade do estabelecimento de vínculos entre os movimentos sindical e LGBT, de forma a enfrentar posições conservadoras manifestas por congressistas em nível federal. Em relação aos direitos trabalhistas, foram destacados os desafios do preconceito no ambiente de trabalho e no próprio movimento sindical, sendo debatidas iniciativas para o levantamento de demandas como uso do nome social e diretos previdenciários; a produção de cartilhas que abordem especificamente tais demandas como a do Programa Conjunto das Nações Unidas sobre o HIV/AIDS (UNAIDS); e a busca por igualdade de oportunidades promovida pela Internacional de Serviços Públicos (ISP) visando a combater o preconceito e a discriminação também no movimento sindical. Dentre as propostas feitas pelo seminário, cabe destacar o incentivo às entidades de base para a realização de seminários sobre a temática LGBT, a promoção de discussão das temáticas LGBT em 
"A luta continua, companheiros... mas não para todos": o

Plenárias e GTs e a construção de parcerias e apoios mútuos de movimentos sociais LGBT para atividades e campanhas com o intuito de conquistar e garantir direitos civis da população LGBT (FASUBRA, 2014). Entretanto, desde então, pouco se avançou no debate sobre as temáticas LGBT nos sindicatos da categoria, inclusive no SINTUFRJ. As discussões sobre as temáticas LGBT contam com a participação de pouquíssimos membros, e menções apenas breves a tais questões são feitas nos documentos produzidos pelo sindicato e no seu próprio website. Em junho de 2016, o GT-LGBT do Congresso do SINTUFRJ não pôde ser realizado por "falta de quórum".

Tendo isso em vista, o objetivo é examinar o esvaziamento das discussões em torno de direitos civis e trabalhistas de servidores técnicoadministrativos LGBT no Sindicato dos Trabalhadores em Educação da Universidade Federal do Rio de Janeiro (SINTUFRJ). O argumento central aponta que o SINTUFRJ assumiu papel primordial na mobilização contra a precarização do trabalho dos TAEs na UFRJ e nas demais universidades federais no Brasil em face da dinâmica excludente do processo de globalização e seus impactos nas condições de trabalho nessas instituições de ensino superior. Entretanto, o engajamento do SINTUFRJ na transformação dos TAEs em sujeitos políticos e sociais não pressupôs a eliminação de padrões heteronormativos no estabelecimento de objetivos, estratégias e mecanismos de reivindicação pelos membros do sindicato, de forma a se enfraquecer a atuação do grupo de trabalho LGBT do SINTUFRJ e se reduzir o peso das temáticas LGBT nas propostas do sindicato. Não se gera, assim, o reconhecimento pleno da diferença na sua dimensão de riqueza, pré-requisito para uma luta que enseje uma transformação social mais ampla.

\section{Fundamentação teórica}

\section{A masculinidade, a heterossexualidade e o universo do trabalho}

Para Butler (2003), o gênero é uma performance produtora de significados e não pode ser concebido como a inscrição cultural de significado num sexo previamente dado. Ele designa o aparato de produção a partir do qual os próprios sexos são estabelecidos. Ele cria uma falsa noção de estabilidade, em que uma matriz heterossexual seria garantida por dois sexos fixos e coerentes e mantida pela repetição de atos, gestos e signos culturais (BUTLER, 2003). Nesse sentido, tal matriz 
é sustentada por uma ordem heteronormativa, que expressa as expectativas, as demandas e as obrigações sociais que derivam do pressuposto da heterossexualidade como natural, além das prescrições que embasam processos sociais de regulação e controle (MISKOLCI, 2009).

No que diz respeito aos homens, Baubérot (2013) argumenta que, ao longo de infância e adolescência, meninos são levados a interiorizar formas de pensamento e maneiras de agir que os preparam para a tomada de posição no encadeamento das relações de poder e dominação. Nesse raciocínio, o menino se torna homem porque, à medida que se realiza o trabalho de maturação biológica, as instituições que participam da sua socialização encarregam-se de transmitir a ele o hábito viril e o conjunto de disposições físicas e psíquicas que lhe permitirão desempenhar seu papel, uma vez chegada a maturidade. $\mathrm{Na}$ família, o papel fundamental no aprendizado das qualidades e papeis destinados a cada sexo é interiorizado a partir da repartição tradicional de tarefas. Além disso, os grupos que participam de sua iniciação viril como bandos ou gangues - apresentam-se como antíteses do lar, universo no qual garoto é mantido em sua meninice. Tais grupos reforçam a dureza, os jogos de força e a coragem, bem como o desejo por desafios e autoafirmação. Para aqueles indivíduos de menor renda, o status de homem apareceu, em grande parte, ligado ao emprego da força em atividades produtivas e ao domínio de conhecimentos que não se adquirem na escola. Porém, a virilidade não aparece nesse contexto como um atributo natural do homem, mas um fruto de processos educativos e sociais que visam a perpetuar a dominação masculina (BAUBÉROT, 2013).

Como resultado desses processos educativos e sociais nas classes trabalhadoras, a imagem de corpo masculino disposto ao trabalho e à luta se impôs no imaginário político da primeira metade do século XX. $\mathrm{Na}$ segunda metade do século XX, amplamente desvalorizada pelas transformações do trabalho e das mudanças sociais, a afirmação brutal do masculino em ato e em palavra veio perdendo função de referência identitária. A demonstração viril tem cada vez menos apoio, mas não desapareceu completamente nos meios de trabalho, nem a própria naturalização da divisão sexual, na qual mulheres estariam acantonadas unicamente nos espaços domésticos. Nos sindicatos, a disciplina e a moralidade se encarnaram na resistência ao capitalismo e na valorização do trabalho, em que locais como a fábrica se tornaram campos de luta e 
"A luta continua, companheiros... mas não para todos": o

discussão. A imagem do trabalhador viril deve também muito à construção de um arquétipo em que se misturam atributos físicos, virtudes morais e qualidades psicológicas, uma construção social e política que se casa com o movimento de disciplinarização e moralização dos trabalhadores desde o século XIX (PILLON, 2013).

\section{O novo sindicalismo}

Diante da crescente hipertrofia do setor terciário e da submissão da educação, saúde, cultura e lazer à lógica do capital, o capitalismo contemporâneo - que assumiu um perfil mais bem definido a partir da década de 1970 - trouxe como características fundamentais o financeirismo, o rentismo, e a concepção equivocada de que os conflitos no ambiente do trabalho poderiam ser remediados pelo consenso obtido por meio da democracia representativa. No entanto, essas características enfrentaram resistência. A pressão exercida pelos movimentos organizados de trabalhadores, a contracultura e a revolução nos costumes projetaram novos atores no cenário político como agentes da mobilização anti-exclusão promovida pelo capitalismo. Os sindicatos, definidos desde o século XIX como associações de trabalhadores que buscavam negociações entre a representação coletiva desses trabalhadores e seus respectivos empregadores, discutiam os termos e as condições associados ao emprego (FARBER, 2001). Entendidos como coalizões de trabalhadores que procuravam negociar o compartilhamento de ganhos econômicos com os empregadores, eles operavam como veículos por meio dos quais esses trabalhadores obtinham uma oportunidade de voz diante de seus empregadores para trazer demandas relacionadas ao trabalho (HIRSCHMAN, 1970).

A reestruturação do capitalismo numa base neoliberal apontou não apenas para a flexibilização dos processos de trabalho, mercados, produtos e padrões de consumo, mas também a menor estabilidade do trabalhador, a precariedade do emprego e das relações de trabalho e a desfragmentação da classe operária, o que gerou a perda de direitos, o aumento do desemprego e a redução da força dos sindicatos. Trabalhadores desunidos começaram a perder a resiliência a ataques de capital. Assim, a classe trabalhadora viu-se cada vez mais desmobilizada em sua luta em face da extrema fragmentação dos modos de agregação dos trabalhadores (BEAUD, 1987). Contudo, a importância da luta dos sindicatos não pode ser completamente descartada, nem a morte do 
"sujeito revolucionário" pode ser decretada, mas as condições do protagonismo político dos trabalhadores precisam ser revistas para que possam persistir na luta contra a ação opressora da capital (NETTO; BRAZ, 2006).

Na sociedade brasileira, muitos sindicatos desenvolveram novas funções no contexto do que Santana (1999) chama de "novo sindicalismo". Segundo o autor, os "novos sindicalistas" afirmam que o sindicalismo anterior a 1964 não teria sido autônomo e independente, porque os sindicatos foram então criados por interesses políticos em benefício dos que estavam no poder. Os novos sindicalistas procuraram se distinguir das lideranças passadas, distanciando-se da estrutura sindical corporativa ligada aos interesses do Estado, criticando radicalmente os mecanismos de união ao Estado e reivindicando a democratização da estrutura sindical (SANTANA, 1999).

$\mathrm{O}$ "novo sindicalismo" parecia garantir à classe trabalhadora um canal fundamental para a representação de suas demandas antigas e novas. A participação em sindicatos oferecia ao trabalhador um conjunto de benefícios pessoais e coletivos. Exemplos de benefícios coletivos incluem reivindicações por melhores condições de trabalho, promoção da saúde e segurança dos trabalhadores e fornecimento de canais apropriados para denunciar o assédio moral de empregadores. Como exemplo de benefícios pessoais, é possível indicar investimentos em treinamento e educação (FARBER, 2001).

O "novo sindicalismo" entendeu que a cidadania não é apenas uma tentativa de eliminar o ônus da pobreza nos níveis mais baixos da sociedade, mas assumiu o aspecto de ações, promovendo uma mudança total no padrão de desigualdade social. A cidadania não apenas pretende elevar o nível do andar inferior do edifício social, mas também remodelar todo o edifício (MARSHALL, 1967). O novo sindicalismo no Brasil vê que a situação mundial se torna insustentável, pois há um aprofundamento da competitividade, uma produção de novos totalitarismos e o crescente empobrecimento das massas. Nesse cenário, em que a tirania do dinheiro e da informação aparece como pilar de uma situação em que o progresso técnico é explorado por um pequeno número de atores globais em benefício exclusivo (TAVARES, 2000), tornou-se necessário lutar por inclusão social, o que requeria uma perspectiva crítica do mundo e do papel da força de trabalho. 
"A luta continua, companheiros... mas não para todos": o

À luz do processo de exclusão, o desemprego está se tornando comum, a pobreza aumenta, e tudo isso é resultado da deterioração do valor do trabalho em um "mundo de exclusões", agravado pela desproteção social, uma marca do modelo neoliberal, que também é criador de insegurança (SANTOS, 2000). No entanto, como Tavares (2000) argumenta, uma nova centralidade dos atores sociais forma a base para uma nova política. Em contraste com a alienação das massas, surge uma nova consciência de solidariedade e cidadania, com uma nova filosofia moral oposta à dos valores mercantis, a qual incorpora também as temáticas relevantes à população LGBT.

\section{O novo sindicalismo e a política LGBT hoje}

Um dos efeitos da globalização foi a precarização das condições de trabalho de modo geral, inclusive atingindo os trabalhadores técnicoadministrativos em educação no Brasil, o que gera a sua objetificação. Os sindicatos das universidades públicas brasileiras podem ser locais de luta pela transformação dessa lógica de objetificação dos servidores na estrutura contemporânea da educação superior no Brasil para sua colocação enquanto sujeitos políticos e sociais (SANTOS, 2000; OLIVEIRA, 1999). O movimento sindical trouxe ao espaço público demandas de redistribuição econômica, mas, ao longo de muito tempo, ignorou as reivindicações específicas das populações negras, das mulheres e da população LGBT. Em face de um novo repertório de demandas num cenário político em que as instituições tradicionais como o Estado passavam a ser questionadas em suas representatividade e autoridade, os sindicatos viram a necessidade de ampliar o diálogo com novos movimentos sociais que afirmavam que o privado era político e a desigualdade ia além da esfera econômica (MISKOLCI, 2016).

Nesse contexto, os sindicatos se viram com o desafio de conciliar uma luta geral, que vinha sendo travada com relação à desigualdade econômica e à precarização das condições de trabalho, com outras mais específicas, como as que reivindicavam sindicalistas LGBT. Cumpre lembrar que, por mais que demandas de movimentos como os LGBTs tenham sido amplamente divulgadas, elas atingiram apenas uma minoria da população, de forma que orientações sexuais e identidades de gênero não-heteronormativas continuam sendo tratadas, na prática, como "indigestas" e uma "mistura de pecado, sem-vergonhice e doença" por grande parte da população brasileira. O principal fator político de 
união de indivíduos LGBT é a luta específica relacionada ao combate à posição marginalizada e à discriminação a que estão sujeitos. A tentativa de assimilar padrões heterossexuais na construção de relações sociais por indivíduos LGBT está sujeita a suprimir a vivência plena de suas sexualidades e orientações de gênero em face da permanência do estigma em torno desses indivíduos (FRY; MCRAE, 1985; GREEN, 1999).

Os princípios tayloristas - como a prescrição dos modos e tempos das operações e a cronometragem - desapossaram gradualmente os trabalhadores de grande parte de sua autonomia de organização. A lógica do ofício deixa lugar a um novo enquadramento dos assalariados, baseado em contratações das formações, qualificações e remunerações. Contudo, o taylorismo não aboliu a primazia de trabalhadores viris em uma série de tarefas, ainda que formas de sociabilidade viril tenham sido enfraquecidas pelos modos de vida e trabalho das jovens gerações que foram beneficiadas pelo prolongamento dos estudos, pela aquisição de diplomas profissionais e pela imagem da promoção social pelo trabalho intelectual. Deslegitimados pelas novas formas de organização do trabalho, pela aquisição de títulos escolares e pela destruição dos laços comunitários, os valores da virilidade são também afetados pelo desemprego em massa, mas, no âmbito da organização sindical também enfraquecida com a implementação de reformas neoliberais -, os valores da combatividade e do esforço não desapareceram completamente, bem como posturas misóginas e LGBTfóbicas (PILLON, 2013).

Diante da estigmatização vigente na sociedade - inclusive no ambiente de trabalho -, diversos membros da população LGBT buscaram separar a esfera privada da pública por prudência ou pudor, negociando sua autoapresentação em termos de orientação sexual e identidade de gênero muito em função dos lugares, ambientes e situações. Exibir a virilidade poderia também ser uma forma de expressar adesão a uma forma de identidade individual e/ou coletiva. No âmbito das relações de trabalho - em especial em ambientes homossociais -, as relações entre homens transcendiam barreiras de idade, classe e raça, mas a possibilidade de desejo homossexual aparecia como ameaça à coesão do grupo; daí, procura-se justificar a negação da existência, pelo menos latente, de desejos de natureza homossexual. $\mathrm{O}$ medo da homossexualidade impregna culturas homossociais em ambientes de trabalho ou na organização sindical, o que leva à acentuação de condutas machistas e à exacerbação da violência 
"A luta continua, companheiros... mas não para todos": o

LGBTfóbica. Nesses ambientes, membros que não se adequam aos padrões de virilidade impostos são objetos de piadas com conotação sexual, muitas vezes usadas como forma de testar sua virilidade (TAMAGNE, 2013).

No Brasil, a homossexualidade não é colocada como uma conduta criminosa desde os primeiros anos após a independência, e existem leis estaduais e municipais que combatem a discriminação por orientação sexual e identidade de gênero. Entretanto, o preconceito e a discriminação permanecem por convenções que hierarquizam as relações sociais ligadas a identidades de gênero e orientações sexuais como lícitas ou ilícitas e se mostram pouco ou nada afetadas pelo desenvolvimento de iniciativas voltadas para a inclusão da população LGBT. Grande parte da população brasileira reconhece a superioridade da masculinidade heterossexual, de forma que homens nãoheterossexuais visam a se proteger da exposição, da humilhação e dos maus tratos dos quais mulheres e "afeminados" são alvos (MISKOLCI, 2013, 2016). A necessidade de manutenção de uma posição de domínio e controle que os proteja de tais ameaças explica também por que mesmo homens que vivem abertamente a homossexualidade continuam a reiterar padrões heteronormativos, inclusive no ambiente sindical.

\section{Procedimentos metodológicos}

Este estudo exploratório contou não apenas com a pesquisa documental do material produzido pelo SINTUFRJ e pela FASUBRA acerca de temáticas LGBT a fim de identificar as principais iniciativas debatidas pelas organizações sindicais de TAEs acerca dessas questões, mas também bibliográfica para mapear os principais conceitos e argumentos acerca das relações de gênero e das questões relacionadas à orientação sexual em movimentos sindicais.

Além disso, foram também realizadas entrevistas semiestruturadas com dez servidores técnico-administrativos em educação do SINTUFRJ em setembro de 2016, sendo cinco homens e cinco mulheres. Desses, dois homens se identificavam como gays, e uma mulher se identificava como lésbica. Não foram encontrados transgêneros para a realização das entrevistas. Todos os entrevistados estavam na faixa etária de 30 a 40 anos. Os dois homens gays e um heterossexual declararam-se "negros", enquanto os demais se viam como "brancos". A mulher lésbica declarou-se "negra", e, entre as mulheres 
heterossexuais, uma se declarou "negra", e as outras três, "brancas". No que diz respeito à religião, quatro sindicalistas heterossexuais - dois homens e duas mulheres - declararam-se "evangélicos", enquanto os dois homens gays disseram participar de religiões de matriz africana. Um homem heterossexual declarou-se "católico", como duas mulheres heterossexuais. A mulher lésbica definiu-se como "ateia".

O objetivo das entrevistas era identificar o conhecimento e a participação dos entrevistados em debates acerca das temáticas LGBT no SINTUFRJ e a forma como viam o tratamento de membros LGBT do sindicato. Todas as entrevistas foram realizadas em diferentes departamentos e institutos no Campus Fundão da UFRJ, onde também se localiza a sede do sindicato. Cumpre destacar que um dos autores é filiado ao SINTUFRJ desde 2015 e participa das discussões do GT-LGBT desde 2016.

\section{Resultados}

Segundo o estatuto do SINTUFRJ, a luta do sindicato contra a precarização das relações de trabalho dos TAEs resultante do processo de globalização tem sido constante e pode-se, portanto, observar seu papel fundamental na luta pelos direitos dos TAEs da UFRJ. Essa luta se enquadra nos objetivos gerais do SINTUFRJ, que podem ser resumidos conforme se segue: lutar pela melhoria e preservação das condições de trabalho da categoria; lutar em defesa dos direitos e interesses individuais e coletivos dos trabalhadores e trabalhadoras da UFRJ; lutar em defesa das liberdades individuais e coletivas, pelo respeito à justiça social, pelos direitos fundamentais de homens e mulheres e pelo fim de toda e qualquer forma de exploração e opressão; defender a solidariedade entre os trabalhadores e trabalhadoras da UFRJ para a concretização da paz e do desenvolvimento em escala global (SINTUFRJ, 2010).

Ao buscar a interação com movimentos sociais que lutam pelos direitos civis e trabalhistas de negros, mulheres e LGBTs, o SINTUFRJ procurou colocar-se formalmente como um instrumento de emancipação política e humana ao defender ideias no campo da consciência de classe e de garantia de direitos. O GT-LGBT coloca, no website do sindicato, que, dentre suas propostas, ocupa papel central o enfrentamento do machismo e da LGBTfobia em todas as suas formas de manifestação (SINTUFRJ, s.d.). O sindicato teria, assim, supostamente uma ação 
"A luta continua, companheiros... mas não para todos": o

voltada para o combate a ações sistêmicas que criam obstáculos ao usufruto dos direitos de cidadania de pessoas com diferentes orientações sexuais e identidades de gênero.

Entretanto, grande parte dos entrevistados não manifestou posturas de inclusão da população LGBT no sindicato e na própria Universidade, nem tinham conhecimento dos debates no sindicato que envolvem essa população ou interesse por eles. Alguns inclusive se referem a membros dessa população de maneira pejorativa, utilizando termos como "viado", "boiola" ou "queima-rosca" em referência particularmente a homens gays, e um deles chega a insinuar que membros da população LGBT não reuniriam características como a coragem e a determinação, ligadas ao estereótipo do sindicalista. "Imagina botar um queima-rosca pra gritar lá no palanque e enfrentar bomba de gás lacrimogêneo numa manifestação ? Vão todos se cagar de medo ! Tem que ter coragem pra estar na luta !", disse um dos entrevistados.

Outros se dizem mais "tolerantes", mas acreditam que o sindicato não é o espaço para o debate sobre temas LGBT. "Eu tolero todo mundo. A gente aqui não liga se o cara é hetero, viado... O que importa é que ele lute pela melhoria da classe, pela melhoria dos salários. Tem que ter coragem", disse um dos homens heterossexuais entrevistados. "Eu acho que o foco aqui é lutar contra a exploração e pela melhoria da universidade. Essa coisa de LGBT não tem que estar presente aqui", disse outro homem heterossexual entrevistado.

A posição manifesta pelos entrevistados homens heterossexuais é semelhante às da maior parte das mulheres heterossexuais. "Aqui a gente luta pela melhoria das condições de trabalho de todos... O espaço para debater os temas de LGBTs é outro", disse uma entrevistada. Uma outra entrevistada - mulher, negra e heterossexual - reconhece a importância do sindicato no debate sobre questões relacionadas à raça e ao gênero feminino, mas não parece demonstrar interesse sobre discussões específicas sobre LGBTs. "Aqui já temos GTs que falaram sobre racismo, a situação da mulher aqui na Universidade... Sobre LGBTs... Bem, acho que já falaram sobre isso, mas eu não estou muito antenada”.

Os dois homens gays e a mulher lésbica entrevistados evidenciaram a invisibilidade das pautas LGBT nas discussões do SINTUFRJ. "Tem o GT LGBT ? Tem. Mas é só pra ficar bonito na foto. 
Nada do que veio da FASUBRA repercute aqui quando o tema é LGBT. Você vê que, em junho [de 2016], não tinha quórum pro GT", disse um dos entrevistados gays. "Eu acho que os membros LGBT do SINTUFRJ têm medo de dizer o que são. Acho que ficam com medo de ficar visados, ser alvo de piada... Quando aparece uma sugestão do tema, eles se esquivam e preferem fingir que não é com eles", disse o outro entrevistado gay. "Durante as assembleias, o povo ama gritar aqui 'A luta continua, companheiros !'. Mas de que luta eles estão falando ? É por salário ? É pra melhorar plano de carreira ? Ou é pra você incluir realmente as pessoas do jeito que elas são ? Gay, lésbica, trans ? Eu não me sinto companheira deles muitas vezes", disse a entrevistada lésbica.

As piadas e as ridicularizações envolvendo o universo LGBT são frequentes, sendo algo inclusive reconhecido por um dos homens heterossexuais entrevistados, mas que diz que tudo não passa de "brincadeira": "depois de velho, esse cara [um companheiro de sindicato cujo nome não será revelado] resolveu escorregar no quiabo [risos, apontando para um dos sindicalistas próximos a ele durante a entrevista]... A gente sacaneia, brinca... É normal". Além de tanto homens como mulheres heterossexuais assumirem que faziam piadas de cunho sexual com membros do sindicato que se diziam LGBTs ou que suspeitavam que fossem, um dos entrevistados - que se disse evangélico - alegou que não concordava com a inclusão de pautas LGBT no SINTUFRJ por causa de questões religiosas: "Jesus ama o pecador, mas não o pecado dessa gente. Não tem por que trazer esses temas para serem debatidos num espaço como o sindicato".

Uma das mulheres heterossexuais entrevistadas condenava esse tipo de comportamento de muitos sindicalistas, classificado por ela como "preconceituoso". "Detesto preconceito, mas eu acho que muita gente age assim aqui porque veio de uma família machista, pobre, com menos condição... Eu mesma tenho que sempre me policiar com isso. Estou me acostumando com a ideia de ver gente diferente no sindicato e na universidade, mas não fui criada assim", disse ela.

\section{Discussão e análise}

Ainda que o SINTUFRJ tenha assumido papel importante no enfrentamento da exploração econômica dos TAEs e se mostrado integrado a movimentos sociais e populares que se colocam no campo progressista, a defesa formal da livre orientação sexual e das múltiplas 
"A luta continua, companheiros... mas não para todos": o

identidades de gênero não necessariamente conduziu ao enfrentamento da discriminação de gênero e sexualidade no ambiente de trabalho dos TAEs da UFRJ e mesmo dentro do próprio sindicato. Como outras entidades sindicais, o SINTUFRJ sinaliza, com a criação de um GTLGBT, a suposta intenção de promover rupturas no sistema capitalista a partir de uma concepção ampla de emancipação e assim desestabilizar padrões heteronormativos naturalizados na sociedade com o desenvolvimento das relações capitalistas de produção (SECRJ, 2015). Entretanto, a criação desse GT parece ter mais a finalidade de um alinhamento superficial com outros movimentos sociais e a construção de uma causa aparentemente mais democrática para ganhos em termos de visibilidade e reconhecimento, acompanhado da assimilação de um discurso transformador da ordem heteronormativa, sem um efetivo endereçamento de crenças e identidades excludentes dos sindicalistas.

Como ficou evidente nas entrevistas realizadas, a maior parte dos membros do SINTUFRJ naturaliza a heterossexualidade na esfera sindical, como também esvazia, desconhece ou mesmo desmerece o debate sobre as questões civis e trabalhistas LGBT. Reitera-se a ligação do sindicalista a uma noção de masculinidade associada à força, à dureza e até mesmo à agressividade da luta contínua, que gera, em especial entre os homens, relações de camaradagem, como colocara Pillon (2013). "A luta continua, companheiros !" é uma frase constantemente dita pelos homens sindicalistas nas reuniões do SINTUFRJ.

Em vez de contribuir para reverter uma ordem excludente em termos das identidades de gênero e orientações sexuais, o sindicato acaba por consolidar espaços políticos generificados e reiterar a dominação dos interesses e das ideologias associadas à heteronormatividade no movimento sindical. Preservando-se os arranjos patriarcais e heteronormativos dos princípios da luta sindical, a capacidade de definição da agenda de reivindicações do SINTUFRJ continua estrategicamente posicionada nas mãos de homens heterossexuais, que preservam um discurso inclusivo de "tolerância" e de "respeito à diversidade" sem efetivamente promoverem um reconhecimento das diferenças de identidade de gênero e orientação sexual na sua dimensão de riqueza.

O preconceito com relação a LGBTs - principalmente homens homossexuais - fica claro em piadas de cunho machista que os próprios sindicalistas fazem - "depois de velho, esse cara [companheiro de sindicato] resolveu escorregar no quiabo" - e no uso do referencial 
religioso por alguns membros do SINTUFRJ para condenar a orientação sexual dos servidores LGBTs: "Jesus ama o pecador, mas não o pecado dessa gente". Observa-se, neste exemplo, a colocação da homossexualidade como abjeção, espaço no qual a coletividade insere aqueles classificados como ameaças ao bom funcionamento e à ordem social (MISKOLCI, 2009, 2013, 2016), inclusive a sindical.

Muitos membros do SINTUFRJ mostraram desconhecimento ou mesmo desprezo em relação às discussões LGBT. Ainda que integrantes recusem valores morais violentos que instituem a linha de abjeção, eles manifestam a dificuldade de mobilização de outros sindicalistas para as discussões relacionadas aos direitos civis e trabalhistas da população LGBT, o que justifica a irregularidade na realização das reuniões e o baixo quórum nos encontros. Muitos temem a ameaça constante de retaliações e violência pelos próprios membros do sindicato, grande parte criada e residente em comunidades do Rio de Janeiro, marcadas por valores patriarcais, de acordo com uma das entrevistadas. Vê-se, assim, a operação de um processo educativo e social que visa a perpetuar a dominação masculina heterossexual na formação de sindicalistas LGBTfóbicos, na linha indicada por Baubérot (2013).

Por conta disso, muitos membros LGBT do sindicato adotavam comportamentos heterossexuais tidos como discretos ou mesmo não revelavam sua orientação sexual no ambiente de trabalho na UFRJ ou para "companheiros" do próprio sindicato. Compreende-se, assim, por que muitos membros LGBT do sindicato não manifestavam sua orientação sexual, como indicara um dos entrevistados gays, tendo em vista o receio deles de serem ridicularizados ou alvos de chacotas ou outras formas de violência simbólica, como apontara Tamagne (2013).

\section{Considerações finais}

Como lembra Miskolci (2016), a experiência de abjeção deriva do não-cumprimento das expectativas relacionadas ao gênero e à manutenção da heterossexualidade como modelo inquestionável. Nesse sentido, se por um lado o SINTUFRJ lutou para tornar os TAEs sujeitos políticos e sociais, por outro ele contribuiu para que alguns desses servidores fossem continuamente rotulados como abjetos. O esvaziamento do GT-LGBT e a permanência da violência no discurso de sindicalistas contra gays, lésbicas e transgêneros - mesmo sob a defesa do princípio de "tolerância" pelo sindicato - revelam que o foco da luta 
"A luta continua, companheiros... mas não para todos": o esvaziamento das pautas LGBT no Sindicato de Trabalhadores em Educação da Universidade Federal do Rio de Janeiro

sindical continua centrado nas questões de redistribuição econômica, mas pouco fez para eliminar, no ambiente de trabalho na universidade e na sociedade em nível mais amplo, uma ordem de violência simbólica dirigida àqueles que não se enquadram em padrões heteronormativos.

\section{Referências}

BAUBÉROT, Arnaud. Não se nasce viril, torna-se viril. In: CORBIN, Alain; COURTINE, Jean-Jacques; VIGARELLO, Georges. (Ed.) História da Virilidade - Volume 3: A virilidade em crise ? Séculos XX-XXI. Petrópolis: Vozes, 2013, p.189-220.

BEAUD, Michel. História do Capitalismo: de 1500 aos nossos dias. São Paulo: Brasiliense, 1987.

BUTLER, Judith. Bodies that Matter: on the discursive limits of sex. Nova York: Routledge, 2003.

FARBER, Henry. Notes on the Economics of Labour Unions. Princeton University - Working Paper, n. 452, p. 1-24. 2001.

FASUBRA. Carta do I Seminário LGBT da FASUBRA Sindical. Brasília, 21 nov. 2014. Mimeo.

FRY, Peter; MACRAE, Edward. O que é homossexualidade. São Paulo: Brasiliense, 1985 .

GREEN, James N. Além do Carnaval: a homossexualidade masculina no Brasil do século XX. São Paulo: Ed. UNESP, 1999.

HIRSCHMAN, Albert. Exit, Voice and Loyalty. Cambridge: Harvard University Press, 1970.

MARSHALL, Thomas Humphrey. Cidadania, Classe Social e Status. Rio de Janeiro: Zahar Editores, 1967.

MISKOLCI, Richard. A Teoria Queer e a Sociologia: o desafio de uma analítica da normalização. Sociologias, Ano 11, n.21, p.150-182, jan./jun. 2009. 
. Machos e Brothers: uma etnografia sobre o armário em relações homoeróticas masculinas criadas on-line. Estudos Feministas, v.21, n.1, p.301-324, jan./abr.2013.

- Teoria Queer: um aprendizado pelas diferenças. 2 ed. Belo Horizonte: Autêntica, 2016.

NETTO, José Paulo; BRAZ, Marcelo. Economia Política: uma introdução crítica. São Paulo: Cortez, 2006.

OLIVEIRA, Francisco. A Face do Horror. Departamento de Sociologia da Faculdade de Filosofia, Letras e Ciências Humanas - Universidade de São Paulo. São Paulo, 1999. Digitado.

PILLON, Thierry. Virilidade operária. In: CORBIN, Alain; COURTINE, Jean-Jacques; VIGARELLO, Georges. (Ed.) História da Virilidade Volume 3: A virilidade em crise ? Séculos XX-XXI. Petrópolis: Vozes, 2013, p.364-393.

SANTANA, Marco Aurélio. Entre a Ruptura e a Continuidade: visões da história do movimento sindical brasileiro. Revista Brasileira de Ciências Sociais, v. 14, n. 41, p. 103-120, out. 1999.

SANTOS, Milton. Por uma Outra Globalização: do pensamento único à consciência universal. Rio de Janeiro: Record, 2000.

SECRJ. Sindicato marca presença na fundação da UNA-LGBT. SECRJ website, 2015. Disponível em: <http://secrj.org.br/noticias/sindicatomarca-presenca-na-fundacao-da-una-lgbt/> . Acesso em: 23 jun. 2016.

SINTUFRJ. Estatuto do SINTUFRJ. 10 jul. 2010. Disponível em: <http://sintufrj.org.br/estatuto.html>. Acesso em: 24 jun. 2016.

SINTUFRJ. GT LGBT, s.d. Disponível em: <http://www.sintufrj.org.br/ LGBT/>. Acesso em: 23 jun. 2016.

SINTUFRJ. Jornal do SINTUFRJ. Ano XXIV, n. 1156, 19 abr. - 1 maio. 2016.

TAMAGNE, Florence. Mutações homossexuais. In: CORBIN, Alain; COURTINE, Jean-Jacques; VIGARELLO, Georges. (Ed.) História da Virilidade - Volume 3: A virilidade em crise ? Séculos XX-XXI. Petrópolis: Vozes, 2013, p.424-453. 
“A luta continua, companheiros... mas não para todos": o esvaziamento das pautas LGBT no Sindicato de Trabalhadores em Educação da Universidade Federal do Rio de Janeiro

TAVARES, Maria da Conceição. Prefácio. In: SANTOS, Milton. Por uma Outra Globalização: do pensamento único à consciência universal. Rio de Janeiro: Record, 2000, p.2-3. 


\section{"The fight goes on, comrades ... but not for everyone": the emptying of LGBT discussions at the Union of Education Workers of the Federal University of Rio de Janeiro}

ABSTRACT: The purpose is to examine the emptying of discussions on LGBT civil and labor rights at the Union of Workers in Education of the Federal University of Rio de Janeiro (SINTUFRJ, its acronym in Portuguese). The central argument points out that the SINTUFRJ assumed a primordial role in mobilizing against the precariousness of the work of education technical-administrative workers (TAEs) at UFRJ and other federal universities in Brazil. However, the involvement of SINTUFRJ in the transformation of TAEs into political and social subjects did not presuppose the elimination of heteronormative standards in the establishment of union objectives and strategies to weaken the work of the SINTUFRJ LGBT working group and reduce the weight of LGBT issues in union proposals.

KEYWORDS: Heteronormativity. Unionism. Education technicaladministrative worker. Globalization. Federal universities.

Diego Santos Vieira de JESUS

Doutor em Relações Internacionais pela PUC-Rio e docente e pesquisador do Programa de Mestrado Profissional em Gestão da Economia Criativa da ESPM-

Rio.

Henrique de Oliveira Santos Vieira de JESUS

Mestrando em Tecnologia para o Desenvolvimento Social pelo Núcleo Interdisciplinar para o Desenvolvimento Social (NIDES / UFRJ).

Recebido em: 23/07/2019

Aprovado em: 01/01/2020 